Short communication

\title{
Clinical outbreak of babesiosis caused by Babesia capreoli in captive reindeer (Rangifer tarandus tarandus) in the Netherlands
}

\author{
Jan H. Bos ${ }^{\mathrm{a}}$, Fokko C. Klip ${ }^{\mathrm{a}}$, Hein Sprong ${ }^{\mathrm{b}}$, Els M. Broens ${ }^{\mathrm{c}, *, 1}$, Marja J.L. Kik ${ }^{\mathrm{d}, *, 1}$ \\ a Ouwehand Zoo, Rhenen, The Netherlands \\ b Laboratory for Zoonoses and Environmental Microbiology, National Institute for Public Health and Environment (RIVM), Bilthoven, The Netherlands \\ c Department of Infectious Diseases and Immunology, Faculty of Veterinary Medicine, Utrecht University, Utrecht, The Netherlands \\ d Department Pathobiology, Faculty of Veterinary Medicine, Utrecht University, Utrecht, The Netherlands
}

\section{A R T I C L E I N F O}

\section{Keywords:}

Babesia

Babesia capreoli

Rangifer tarandus tarandus

Reindeer

Roe deer

\begin{abstract}
A B S T R A C T
From a herd of captive reindeer (Rangifer tarandus tarandus) consisting of two males and seven females with five calves, three calves were diagnosed on post mortem examination with a Babesia capreoli infection. The diagnosis was indicated by PCR and when the other reindeer were examined two adult females and a one-year-old male were Babesia-positive. Molecular characterization of the 18S rDNA of the parasite showed complete identity with known $B$. capreoli sequences. Ixodes ricinus has been demonstrated to be a competent vector for $B$. capreoli from infected roe deer (Capreolus capreolus), the natural host of $B$. capreoli.

The $B$. capreoli infection in these reindeer may have been transmitted by infected ticks (Ixodes ricinus) originating from roe deer living in the forest and meadows surrounding the enclosure.
\end{abstract}

\section{Introduction}

Babesiosis is a tick-borne disease caused by protozoal parasites of the genus Babesia. Tick-transmitted pathogens are becoming increasingly important, however, not all aspects of the transmission dynamics of tick-borne pathogens are known. (Dantas-Torres, 2015; Lindgren and Jaenson, 2006)

Acute Babesia infection can cause hemolysis resulting in hemolytic anemia with icterus and hemoglobinuria. Infected animals may show normocytic, normochromic anemia, a low packed cell volume and red blood cell count and, depending on the stage of the disease, variable counts of white blood cells (Bartlett et al., 2009). Clinical signs can include high fever, hemoglobinuria, jaundice, shaking, myalgia and abdominal pain but asymptomatic infections are also possible.

Babesia spp. multiply within the erythrocytes by asynchronous binary fission which produces gametocytes that can be ingested by blood-feeding arthropods such as castor bean ticks (Ixodes ricinus). Within the tick gut, after conjugation, the gametocytes undergo multiple rounds of fission and migrate to different tissues within the tick. Before transmission further development occurs in the tick's salivary gland (Gray et al., 2010).

Babesia spp. are widespread throughout Europe. In wild and domestic ruminants $B$. divergens, $B$. venatorum and $B$. capreoli are of major importance (Hoby et al., 2009; Rizzoli et al., 2014). B. divergens is found in cattle (Zintl et al., 2003). B. venatorum seems to be common in roe deer (Capreolus capreolus), typically occurring without clinical signs although these have occasionally been described in reindeer in Switzerland (Robert et al., 2008) and the Netherlands (Kik et al., 2011). Asymptomatic roe deer seem to be the mammalian maintenance host of B. capreoli in Europe (Michel et al., 2014; Hoby et al., 2009). In Germany and Switzerland clinical infections have been reported in captive reindeer, alpine chamois (Rupicapra rupicapra), and red deer (Cervus elaphus) (Hoby et al., 2009; Wiegmann et al., 2015). Based on case reports of clinical cases and on tick surveillance, $B$. divergens and $B$. venatorum are considered to be endemic in the Netherlands but $B$. $c a$ preoli has not been described in the Netherlands to date (Wielinga et al., 2009).

Here we describe the first clinical outbreak of babesiosis caused by B. capreoli in captive reindeer in the Netherlands.

\section{Case description}

In 2015 an outbreak of clinical babesiosis occurred in a reindeer population at Ouwehand Zoo in Rhenen, the Netherlands. The reindeer herd consisted of 14 animals: 2 adult males, 7 adult females and 5 calves, all of which had been born in May of that year.

\footnotetext{
* Corresponding authors.

E-mail addresses: e.m.broens@uu.nl (E.M. Broens), m.kik@uu.nl (M.J.L. Kik).

${ }^{1}$ Equal last authors.
} 


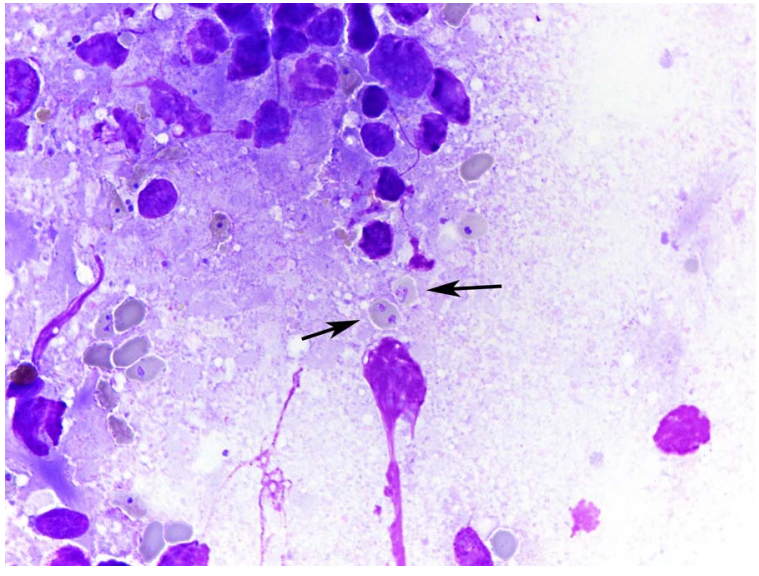

Fig. 1. Cytology of the lung of a reindeer infected with Babesia. The protozoal inclusions are indicated by arrows.

A one-month-old calf (8267) suddenly died without exhibiting clinical signs. At necropsy jaundice of the sclera, pleurae, serosa of the intestines and large vessels as well as hemoglobinuria were evident. The liver was slightly enlarged and yellow. The spleen was enlarged. Cytology was performed on the liver, spleen, lungs and large intestinal contents which were stained with Hemacolor ${ }^{\circ}$ (Merck, Darmstadt, Germany). Cytological examination showed 2-3 $\mu \mathrm{m}$ large intra-erythrocytic inclusions consistent with Babesia spp. (Fig. 1). DNA was extracted from spleen material using the DNeasy blood \& tissue kit according to the manufacturer's instructions (Qiagen, Hilden, Germany). PCR was performed using primers (forward primer: 5'-GACACAGGGAGGTAGTGACAAG- $3^{\prime}$ and reverse primer $5^{\prime}$-CTAAGAATTTCACCTCTGACAGT-3') amplifying the V4 region of the 18S ribosomal RNA gene of Babesia/Theileria (Gubbels et al., 1999). The PCR produced a signal indicating the presence of Babesia and/or Theileria DNA. Two weeks later, another calf of the same age (1888) showed heavy breathing and fever $\left(40.2^{\circ} \mathrm{C}\right.$ ). Procaïnbenzylpenicillin (Dopharma Research B.V. Raamsdonkveer, the Netherlands; $20,000 \mathrm{IU} / \mathrm{kg} /$ day, subcutaneously for 5 days) was administered combined with a single intravenous injection of flunixin meglumine $(1 \mathrm{mg} / \mathrm{kg}$; Finadyne, Intervet Nederland B.V., Boxmeer, the Netherlands). The calf was diagnosed with laryngeal diphtheria and a tracheotomy was performed. A modified tracheal tube was placed under local anesthesia. One week after surgery the condition of the calf suddenly deteriorated and the calf was euthanized.

Necropsy confirmed the initial diagnosis of laryngeal diphtheria. Additional findings included hepatosplenomegaly, dark red kidneys (on cut surface) and light red urine. Intra-erythrocytic inclusions were present in cytology. Histology revealed acute necrosis in the liver and the tubular epithelium of the kidney and hemosiderin pigment in the spleen. PCR on whole blood of the calf produced a signal indicating the presence of Babesia and/or Theileria DNA. In light of these findings the remaining calves were treated with imidocarb dipropionate (Carbesia 8.5\%, Pharmacy Department, Faculty of Veterinary Medicine, Utrecht, the Netherlands) $3 \mathrm{mg} / \mathrm{kg}$ subcutaneously on days $1,2,6,9$ and 21 (Bartlett et al., 2009).

One week later, a one-year-old male reindeer was euthanized due to acute respiratory distress; no post mortem examination was performed. However, in the cytology of a blood smear an estimated $10 \%$ of the erythrocytes contained inclusions consistent with Babesia spp. Subsequently, blood was taken from five adult females (all mothers of newborn calves), one adult male and the remaining calves (which had received three doses of imidocarb propionate at that time) for complete blood count (CBC), blood chemistry and Babesia testing with PCR.

There were no significant changes in $\mathrm{CBC}$ and blood chemistry values of any of the animals. Two adult females (3667 and 5192) tested positive for Babesia/Theileria by PCR (Table 1). Due to the absence of clinical signs or changes in CBC or blood chemistry it was assumed
Table 1

Information, clinical signs and PCR results from all individual reindeer in the herd.

\begin{tabular}{|c|c|c|c|}
\hline ID (sex) & $\begin{array}{l}\text { year of } \\
\text { birth }\end{array}$ & Babesia (PCR) & Clinical signs \\
\hline $9514(q)$ & 2004 & neg & None \\
\hline $9781\left(\sigma^{7}\right)$ & 2015 & neg & $\begin{array}{l}\text { Died without previous signs (30-6- } \\
\text { 2015) }\end{array}$ \\
\hline 3667 (q) & 2009 & pos & None \\
\hline $1888(q)$ & 2015 & pos & $\begin{array}{l}\text { Larynx diphtheria; euthanized (22-6- } \\
\text { 2015) }\end{array}$ \\
\hline 4729 ( & 2015 & neg & None \\
\hline $5192(q)$ & 2013 & pos & None \\
\hline newborn & 2015 & nd & Died (30-5-2015) \\
\hline $8267\left(\sigma^{\prime \prime}\right)$ & 2015 & pos & $\begin{array}{l}\text { Died without previous signs (12-6- } \\
\text { 2015) }\end{array}$ \\
\hline 3427 ( $($ ) & 2014 & neg & None \\
\hline 2013 (q) & 2014 & neg & None \\
\hline $2466\left(\sigma^{1}\right)$ & 2012 & neg & None \\
\hline male $\left(\sigma^{\prime}\right)$ & 2014 & $\operatorname{pos}^{\mathrm{a}}$ & $\begin{array}{l}\text { Died after acute respiratory distress } \\
(22-7-2015)\end{array}$ \\
\hline
\end{tabular}

nd = not done; reindeer within one line are related (mother and calf)

apositive blood smear instead of PCR.

these animals were subclinically infected. Infected adult animals were not treated with imidocarb in order to ensure a good antibody response and thereby reduce herd susceptibility (Bartlett et al., 2009). PCR products from the four positive samples $(1888,3667,5192$ and 8267) were sequenced by dideoxy-dye termination sequencing of both strands and compared with sequences from isolates in GenBank (http://www. ncbi.nlm.nih. gov/). The sequences were aligned and analyzed using BioNumerics 6.6 (Applied Maths, Kortrijk, Belgium). The sequences obtained from the reindeer samples were all identical and $100 \%$ similar to the 18S rDNA B. capreoli sequences in Genbank (Accession number FJ944828 and FJ944827). The $18 \mathrm{~S}$ rDNA sequence from the reindeer parasite exhibited the characteristic substitutions at positions 631 and 663 (from A to G and A to T, respectively) from Babesia divergens rDNA (Malandrin et al., 2010).

Tick dragging throughout the enclosure and examination of the remaining animals yielded no ticks. An I. ricinus nymphal tick was recovered from the clothing of one of the veterinarians, but tested negative for Babesia/Theileria by PCR.

\section{Discussion}

To our knowledge this report describes the first fatal cases of $B$. capreoli infections in captive reindeer in the Netherlands. Apart from five cases in free-ranging chamois (Rupicapra rupicapra) in Switzerland, no fatal cases of babesiosis due to $B$. capreoli have been reported (Hoby et al., 2009).

There is a single report of a fatal case of B. venatorum (formerly called Babesia sp. EU1) infection in a captive reindeer in the Netherlands (Kik et al., 2011). Also, in another Dutch zoo in June 2015 two adult forest reindeer (R. t. fennicus) exhibiting icterus, acute liver necrosis and hemoglobinuria, with cytological intra-erythrocytic $B a$ besia spp. inclusions, tested positive for $B$. venatorum in PCR tests (unpublished data). Based on case reports of clinical cases and on tick surveillance, $B$. divergens and $B$. venatorum are considered to be endemic in the Netherlands but no reports on the occurrence of $B$. capreoli have been published so far (Wielinga et al., 2009). However, B. capreoli was detected in a recent survey in I. ricinus ticks originating from a national park in the Netherlands (unpublished data).

Adult roe deer and reindeer are often subclinically infected with Babesia spp. (Michel et al., 2014; Penzhorn, 2006). Clinical disease has been described (Langton et al., 2003) but appears to occur rarely in adult animals.

In Germany subclinical infections with different Babesia species 
seem to be common in captive reindeer and this might pose a risk for naïve animals (Wiegmann et al., 2015). Clinical signs are usually more severe in naïve and immunocompromised animals (Bartlett et al., 2009). Only the young calves in this population showed clinical signs and died due to a $B$. capreoli infection whereas some adult animals were subclinically infected. Of the four PCR-positive animals, two were young calves (8267 and 1888) and the other two were adult females (3667 and 5192), both mothers of the deceased calves. Positive diagnosis in the one-year-old male was based on the presence of intra-erythrocytic organisms in its blood smear; unfortunately no post mortem or PCR testing were performed.

The route and time of introduction of $B$. capreoli into the reindeer herd is unknown. Since 2011, no new reindeer were introduced into the herd. Despite the fact that no ticks were found on the animals in the herd it is possible that transmission occurred via Babesia-positive ticks. The enclosure of the reindeer herd is surrounded by forest and meadows where roe deer are frequently seen. Roe deer may themselves have acted as a vector for the spread of Babesia-positive ticks. However, as direct contact between roe deer and the captive reindeer can be ruled out in this zoo, it is possible that Babesia-positive ticks may have entered the enclosure on wild small mammals or birds or even from willow branches (Salix spp.) collected from the surrounding area. To prevent new outbreaks of babesiosis the focus should be on the prevention of tick infestation in captive reindeer by use of acaricidal products during the tick season.

\section{Acknowledgements}

We would like to thank Aleksandra Iwona Krawczyk (RIVM), Koen Verstappen (UU) and Marian Broekhuizen-Stins (UU) for their excellent technical assistance and the keepers of the reindeer population for their commitment in performing this study. R. Thomas for proof reading.

\section{References}

Bartlett, S.L., Abou-Madi, N., Messick, J.B., Birkenheuer, A., Kollias, G.V., 2009. Diagnosis and treatment of Babesia odocoilei in captive reindeer (Rangifer tarandus tarandus) and recognition of three novel host species. J. Zoo Wildl. Med. 40, 152-159.

Dantas-Torres, F., 2015. Climate change, biodiversity, ticks and tick-borne diseases: the butterfly effect. Int. J. Parasitol. Parasites Wildl. 4, 452-461.

Gray, J., Zintl, A., Hildebrandt, A., Hunfeld, K.P., Weiss, L., 2010. Zoonotic babesiosis: overview of the disease and novel aspects of pathogen identity. Ticks Tick. Borne. Dis $1,3-10$.

Gubbels, J.M., de Vos, A.P., van der Weide, M., Viseras, J., Schouls, L.M., de Vries, E. Jongejan, F., 1999. Simultaneous detection of bovine Theileria and Babesia species by Reverse Line Blot Hybridization. J. Clin. Microbiol. 37, 1782-1789.

Hoby, S., Mathis, A., Doherr, M.G., Robert, N., Ryser-Degiorgis, M.-P., 2009. Babesid capreoli infections in alpine chamois (Rupicapra r. Rupicapra), roe deer (Capreolus c. Capreolus) and red deer (Cervus elaphus) from Switzerland. J. Wildl. Dis. 45, 748-753.

Kik, M., Nijhof, A.M., Balk, J.A., Jongejan, F., 2011. Babesia sp. EU1 infection in a forest reindeer, the Netherlands. Emerg. Infect Dis. 17 (5), 936-938.

Langton, C., Gray, J.S., Waters, P.F., Holman, P.J., 2003. Naturally acquired babesiosis in a reindeer (Rangifer tarandus tarandus) herd in Great Britain. Parasitol. Res. 89, 194-198.

Lindgren, E., Jaenson, T.G.T., 2006. Lyme Borreliosis in Europe: Influences of Climate and Climate Change, Epidemiology, Ecology and Adaptation Measures. World Health Organization, 18-20. EUR/04/5046250, http://www.euro.who.int/ data/assets/ pdf_file/0006/96819/E89522.pdf. (Assessed 17 March 2017).

Malandrin, L., Jouglin, M., Sun, Y., Brisseau, N., Chauvin, A., 2010. Redescription of Babesia capreoli (Enigk and Friedhoff, 1962) from roe deer (Capreolus capreolus): isolation, cultivation, host specificity, molecular characterisation and differentiation from Babesia divergens. Int. J. Parasitol. 40, 277-284.

Michel, A.O., Mathis, A., Ryser-Degiorgis, M.-P., 2014. Babesia spp. in European wild ruminant species: parasite diversity and risk factors for infection. Vet. Res. 45, 65.

Penzhorn, B.L., 2006. Babesiosis of wild carnivores and ungulates. Vet. Parasitol. 138, $11-21$.

Rizzoli, A., Silaghi, C., Obiegala, A., Rudolf, I., Hubálek, Z., Földvári, G., Plantard, O., Vayssier-Taussat, M., Bonnet, S., Spitalská, E., Kazimírová, M., 2014. Ixodes ricinu and its transmitted pathogens in urban and peri-urban areas in Europe: new hazards and relevance for public health. Front. Public Heal. 2, 251.

Wiegmann, L., Silaghi, C., Obiegala, A., Karnath, C., Langer, S., Ternes, K., Kämmerling, J., Osmann, C., Pfeffer, M., 2015. Occurrence of Babesia species in captive reindeer (Rangifer tarandus) in Germany. Vet. Parasitol. 211, 16-22.

Wielinga, P.R., Fonville, M., Sprong, H., Gaasenbeek, C., Borgsteede, F., van der Giessen, J.W., 2009. Persistent detection of Babesia EU1 and Babesia microti in Ixodes ricinus in the Netherlands during a 5-year surveillance: 2003-2007. Vector Borne Zoonotic Dis. 9 (1), 119-122.

Zintl, A., Mulcahy, G., Skerrett, H.E., Taylor, S.M., Gray, J.S., 2003. Babesia divergens, bovine blood parasite of veterinary and zoonotic importance. Clin. Microbiol. Rev. 16, 622-636. 